\title{
Uma Biopolítica da Indiferença
}

\section{CAPONI, $\mathrm{S}$.}

Uma sala tranquila: neurolépticos para uma biopolítica da indiferença. São Paulo: LiberArts, 2019. 2.016p.

\author{
| ${ }^{1}$ Atilio Butturi Junior I \\ 1 Linguística, Universidade Federal de Santa Catarina. Florianópolis-SC, Brasil (atilio.butturi@ufsc.br). ORCID: 0000-0002-9985-2259 \\ Recebido em: 03/11/2019 \\ Aprovado em: 16/12/2019 \\ Revisado em: 17/09/2020
}

DOI: http://dx.doi.org/10.1590/S0103-73312020300333

O novo e necessário livro de Sandra Caponi lança mais uma vez o olhar foucaultiano da autora para problematizar as relaçóes entre a medicalizaçáo e o que Caponi tem definido como uma "hermenêutica psiquiátrica de si mesmo". No caso desse Uma sala silenciosa, o que o leitor encontra é uma pesquisa pungente, realizada na biblioteca do hospital Sainte-Anne, em Paris, entre 2017 e 2018, e que resgata a narrativa de um êxito, devidamente colocado em xeque: o aparecimento da clorpromazina e dos neurolépticos como ponto de viragem para uma suposta revolução na farmacopsiquiatria.

Uma sala tranquila, como o próprio título indica, volta-se para as delicadas redes de saber-poder que produzem controle e docilizaçáo, nos moldes pensados por Michel Foucault - seja a respeito da prisão, seja a respeito do poder médicopsiquiátrico. Assim como Foucault, Caponi também vai lançar seu olhar arguto sobre a ubiquidade dos saberes psiquiátricos e seus efeitos nos corpos - um poder ubíquo e por vezes ubuesco, que fabrica nossa "alma moderna".

Organizado em seis capítulos, o escrito busca traçar uma arqueogenealogia dos neurolépticos - notadamente, a clorpromazina e a recente risperidona -, fazendo 
notar a rede de discursos e práticas - médicas, jurídicas, midiáticas, econômicas que, desde a década de cinquenta, produzem uma narrativa de êxito biológico, por um lado, e extensas e variadas modalidades de normalização e de controle para os pacientes. O livro de Caponi sugere uma inversão, e questiona: de que êxito se fala quando se recorre à narrativa triunfalista da medicalização psiquiátrica?

Assim como em Preciado (2008), evoca as estratégias tecno-biopolíticas (e "farmacopornográficas) que tiveram espaço na invenção e no consumo das pílulas anticoncepcionais, os neurolépticos são tomados por Caponi como dispositivos, e sua descrição problematiza justamente o modelo explicativo centrado na doença de que se vale a Psiquiatria, que permite que os discursos e práticas sejam produzidos a partir de uma insistência naturalista de causação, hoje adensada com a hipótese (não comprovada) de uma origem dopamonérgica, que a pesquisa irá contemplar.

A escolha certeira da autora passa por três frentes: primeiro, pela rica documentaçáo e pelos movimentos explicativos dos arquivos a que teve acesso, que remontam ao ano de 1952, na França, e a difusão para os Estados Unidos; depois, pelo debate que traça com a bibliografia da área, seja para aproximar-se criticamente (como nos casos de Parada, Whitaker, Missa ou Moncrieff), seja para dar a ver as incongruências do que chama de uma hagiologia, materializada no texto de Judith Swazey (Chlorpormazine in Psiquiatry, de 1974), espécie de clássico histórico sobre a clorpromazina sobre o qual Caponi se debruça cuidadosamente, mostrando ambiguidades, lacunas, silenciamentos; por fim, pela tomada dos enunciados sobre a indiferença, presentes em muitos textos fundadores (escritos pela equipe de médicos coordenada por Jean Delay e Pierre Deniker, no Hospital Psiquiátrico Sainte-Anne, a partir de 1952) e que traçam uma relação biopolítica de cisão entre modalidades de vida e de sujeito.

Desde o primeiro capítulo, a autora lê a chamada "revolução psicofarmacológica" no pós-guerra a partir do conceito de regimes de verdade, de Michel Foucault. Mostra, por meio de ampla pesquisa documental, que não há uma relação epistemologicamente defensável entre, por exemplo, os antibióticos médicos - como a penicilina - e os fármacos psiquiátricos - como a clorpromazina ou a risperidona. O que acontece, a partir das urgências históricas do governo da vida neoliberal, é o aparecimento de uma rede de discursos e práticas, da ordem do saber médicopsiquiátrico, do jurídico e do político que permitem a produção de uma verdade sobre a psiquiatria, na qual a biologia e a cura têm destaque. 
Dessa perspectiva, o capítulo traz à tona a narrativa de origem: descoberta nos anos quarenta como anti-histamínico, usada depois como anestésico, porque "produzia indiferença à dor". Do enunciado da origem, aparece a chave explicativa que percorrerá o escrito de Caponi: é sobre a indiferença que se trata. Laborit, um dos psiquiatras responsáveis pelo uso da clorpromazina, falava em "lobotomia medicinal". Ora, o que os discursos coletados pela pesquisa apontam é que a clorpromazina é sempre descrita como a droga da indiferença e da ordem. Usada para tratamentos de pacientes com diagnósticos tão diversos quanto a esquizofrenia e a psicose, o que marcaria sua presença era a "absoluta indiferença que mostravam os pacientes: nem medo, nem ansiedade, mas apatia e indiferença” (p. 39). Da França aos Estados Unidos, sua proliferação permite criar um novo modelo de tratamento, ambulatorial e silencioso. De outra sorte, os estudos sobre sua ação, pouco conclusivos, partem sempre de um "desequilíbrio neuroquímico" (p. 43) que solicita um futuro (ainda não estabelecido) para ser concluído.

No segundo capítulo, o livro investiga as estratégias de legitimação da clorpromazina - e, a reboque, da Psiquiatria como campo disciplinar. São tomados por objeto três grandes estudos internacionais: o primeiro, na Inglaterra, desenvolvido por Enke \& Enke, de 1954; o de Lehmnan, nos Estados Unidos, também em 1954; o grande estudo randomizado do National Institute of Mental Health, de 1961. Nos três casos, tratava-se de produzir estatísticas de êxito, diante de um aumento exponencial do uso da clorpromazina. Ao mesmo tempo, de silenciar acerca dos achados sobre seus efeitos colaterais graves. Aqui, o texto destaca dois sentidos fundamentais para o conceito de disciplina. Ora, há uma disciplina - lida por Carlos Parada no seu Toucher le cerveau, changer l'esprit, de 2016, e assumida por Caponi - sobre os sujeitos, mas também sobre a instituição psi e a produção do verdadeiro. Destarte, se aparecem os estudos franceses e norte-americanos, seu efeito é notar a ambiguidade constitutiva: as conclusôes são pobres do ponto de vista epistemológico, mas ricas em efeitos políticos. O paciente se torna dócil, passa a se acalmar, pode trabalhar, volta a colaborar. Além disso, aparece a possibilidade de outra intervenção, dessa vez da ordem da temporalidade: cronifica-se a doença, que pode ser tratada em outro espaço e também numa temporalidade estendida. Nesse modelo de cuidado estendido - e devidamente barateado pelo tratamento ambulatorial ou residencial agora possível - a cura, porém, permanece como promessa nesse discurso salvívico de busca pelo Santo Graal. 
O terceiro capítulo discorre sobre a hipótese dopaminérgica na Psiquiatria e sua relação com o DSM - e a inflação nos diagnósticos no DSM. O texto mostra como o modelo fracamente explicativo (do ponto de vista biológico) se enquadra no que Pignarre chama de "biologia menor" (p. 77), visto que será sempre impossível encontrar o marcador biológico suficiente, não obstante os esforços constantes, ainda contemporâneos. É nesse capítulo que o texto se volta mais detidamente para os estudos de Moncrieff, discutindo os modelos da doença e do fármaco.

O capítulo quarto traz à tona dois problemas: primeiro, o da disciplina; o segundo, o dos efeitos colaterais - como a discinesia tardia - jamais enunciados adequadamente nos discursos sobre a clorpromazina. Aqui, de uma perspectiva de distribuição do poder, o que se observa é uma polarização das relaçôes entre médico e paciente. A Psiquiatria e essa nova relação estabelecem um novo modo pelo qual o poder psiquiátrico incide sobre os corpos. Com a clorpromazina, é a utopia do poder soberano que reaparece: silencioso, insidiosos, de táticas mínimas - como uma pílula e a produção da indiferença. O livro mostra o adentramento da clorpromazina e do discurso da cura biológica nos jornais, o patrocínio da indústria farmacêutica e a expansão radical do uso nos EUA - com o Thorazine -, não obstante os efeitos colaterais graves descritos e os processos que surgem. O Thorazine, como a medicina de Foucault, expande-se não apenas para a doença, mas para a vida cotidiana e passa a ser o responsável por controlar os detalhes mínimos das condutas, para além do campo da doença.

Os capítulos V e VI chegam ao presente. No V, o livro problematiza um dispositivo disciplinar e um dispositivo da segurança. Como dispositivo da segurança, do cálculo e da gestáo, o que a clorpromazina coloca em jogo são quatro modificaçôes: os efeitos terapêuticos se multiplicam; a temporalidade se alonga e se torna mais difusa - e os CAPS aparecem como supostos espaços de liberdade; uma nova semiologia da confissão e do registro aparece; o sistema de autoridade do psiquiatra se expande. Aqui, Caponi é peremptória: o saber psiquiátrico não é biológico nem médico, mas se vale da força discursiva dessa "marcação médica" para produzir seus efeitos, muitas vezes de acordo com estratégias ubuescas (p. 146).

Nesse novo dispositivo da segurança, o pacto exige um compromisso do sujeito contra o risco e a Psiquiatria se espraia na condição de detectar e silenciar todo o risco, que se multiplica e vai, como observado no capítulo IV, às condutas cotidianas. É nessa topologia ubíqua que Caponi faz surgir um problema ainda 
candente: a medicalização da infância, seja com a ritalina para o TDAH (de que já se ocupou a autora em textos seminais), seja com a risperidona (um neuroléptico) para conter condutas comuns, que agora atendem por vários diagnósticos como aquele, ubuesco, de transtorno de oposição desafiante. O livro apresenta os deslocamentos do DSM e a produção de um continuum entre infância e vida adulta, repleto de implicações. Ademais, deixa ver a crescente imposição de políticas públicas de medicalização para crianças que nos produzem, desde sempre, a partir de neuronarrativas - a que devemos resistir.

Ao encerrar o texto, Caponi retoma justamente nossa capacidade de resistência e de produção de uma postura crítica, nos moldes kantianos retomados por Michel Foucault, destacadamente nos anos oitenta. Dessa perspectiva, cabe o questionamento sobre a identidade - e a bioidentidade - e um esforço sempre contínuo de reinvenção das subjetividades. É desse lugar crítico e fundamental que escreve Sandra Caponi, em um livro essencial.

\section{Referências}

PARADA, C. Toucher le cerveau, changer l'esprit. Paris: PUF, 2016.

PRECIADO, P. B. Texto yonque. Madrid: Espasa, 2008. 